\title{
Differentially Expressed Proteins in Chronic Active Hepatitis, Cirrhosis, and HCC Related to HCV Infection in Comparison With HBV Infection: A proteomics study
}

\author{
Jamal Sarvari ${ }^{1,2,5}$, Zahra Mojtahedi ${ }^{1}$, Seyed Ali Reza Taghavi ${ }^{3}$, Yasuhiro Kuramitsu ${ }^{5}$, \\ Mahmoud Shamsi Shahrabadi ${ }^{4}$, Abbas Ghaderi ${ }^{1,{ }^{*}}$, Kazuyuki Nakamura ${ }^{5}$ \\ ${ }^{1}$ Institute for Cancer Research, Shiraz University of Medical Sciences, Shiraz, IR Iran \\ 2 Department of Bacteriology and Virology, Shiraz University of Medical Sciences, Shiraz, IR Iran \\ ${ }^{3}$ Department of Internal Medicine, Shiraz University of Medical Sciences, Shiraz, IR Iran \\ ${ }_{5}^{4}$ Department of Virology, Tehran University of Medical Sciences, Tehran, IR Iran \\ ${ }^{5}$ Department of Biochemistry and Functional Proteomics, Yamaguchi University Graduate School of Medicine, Yamaguchi, Japan \\ ${ }^{*}$ Corresponding author: Abbas Ghaderi, Institute for Cancer Research, Shiraz University of Medical Sciences, Shiraz, IR Iran. Tel: +98-7112303687, Fax: +98-7112304952, E-mail: ghade- \\ ria@sums.ac.ir.
}

Received: September 30, 2012; Revised: December 25, 2012; Accepted: April 19, 2013

\begin{abstract}
Background: Hepatocellular carcinoma is a highly progressive cancer in the case of late diagnosis which is frequently associated with HBV and HCV viral infections.

Objectives: To identify differentially expressed serum proteins among three main stages of HCV infection and healthy individuals, and their comparisons with sera from patients with the same stage of HBV infection.

Patients and Methods: Two-dimensional polyacrylamide gel electrophoresis combined with liquid chromatography-tandem mass spectrometry was performed on 47 sera from healthy volunteers, those with chronic active hepatitis, cirrhosis and HCC patients associated with HBV and HCV infections.

Results: Among these, 62 spots were differentially expressed ( $\geq 1.5$ fold; $\mathrm{P}<0.05$ ), of which 42 spots that corresponded to 15 proteins were identified by liquid chromatography-tandem mass spectrometry. CD5-like antigen (CD5L) was differentially expressed between cirrhosis and HCC patients with HCV infection. Leucine-rich $\alpha$-glycoprotein (LRG) and haptoglobin (HP) $\alpha 2$ isoforms differed in the HCC that was associated with either $\mathrm{HCV}$ or HBV infections.

Conclusions: CD5L might be a useful biomarker for early diagnosis of HCC in HCV cirrhotic patients. LRG and HP $\alpha 2$ isoforms could be potential markers for distinguishing viral HCC. Our results also further support the presence of varying molecules involved in hepatocarcinogenesis in HBV when compared with HCV infection.
\end{abstract}

Keywords: Cirrhosis; Hepatitis B Virus; Hepatitis C Virus; Hepatocellular Carcinoma

\section{Background}

Hepatocellular carcinoma (HCC) is the seventh most frequent cancer and the third cause of mortality from cancer worldwide (1). Its major risk factors are hepatitis B virus (HBV), hepatitis C virus (HCV), aflatoxin B1 exposure, and alcohol consumption $(1,2)$. Approximately 350 million individuals are infected with HBV which is the underlying reason of 50\% of HCC cases, and 170 million are infected with HCV which is the cause of $30 \%$ of HCC cases $(3,4)$. About $20 \%-30 \%$ of patients usually develop liver cir- rhosis, from which $80 \%-90 \%$ of HCC cases arise (1). HCC occurs at an annual rate of $1 \%-7 \%$ in HCV-infected cirrhotic patients, and 3\%-8\% in HBV-infected cirrhotic patients (5, $6)$. Therefore, HCC is considered a predictable cancer for which screening is generally recommended in high-risk groups such as cirrhotic patients (7). Alpha-fetoprotein is the most widely used serum biomarker for the detection of HCC, but has less reliability during the early stages of HCC (8). While surgical resection or liver transplant remains the most effective options for curing HCC, the

Implication for health policy/practice/research/medical education:

By a proteomic approach, we identified differentially expressed proteins in the sera from CAH, cirrhosis and HCC related to HCV infection. CD5 like antigen (CD5L) was increased in HCC-HCV compared to HCV- cirrhotic patients that might be a useful biomarker for early diagnosis of HCC in HCV cirrhotic patients. Moreover, for the very first time, we compared the serum proteomes of these three main stages of HCV infection with the same stages of HBV infection. We found down regulation of AGP in HCV-cirrhotic patients compared to those with HBV and up regulation of leucine-rich $\alpha \pm 2$-glycoprotein (LRG), and heptoglubin (HP) $\mathrm{I} \pm 2$ isoforms in HCC-HBV cases compared with HCC-HCV infection that could be potential markers distinguishing viral HCC. Further studies are required to determine the feasibility of the identified proteins as disease biomarkers for diagnosis, prognosis and therapy guidelines. Copyright ( ) 2013, KowsarCorp.; Licensee Kowsar Ltd. This is an Open Access article distributed under the terms of the Creative Commons Attribution License (http:/ creativecommons.org/licenses/by/3.0), which permits unrestricted use, distribution, and reproduction in any medium, provided the original work is properly cited. 
majority of cases are not candidates for surgery because of their interahepatic or distant metastasis at the time of diagnosis (9). More investigations to find useful biomarkers for early diagnosis and elucidative mechanisms of hepatocarcinogenesis as new therapeutic targets are urgently needed for HCC. There are substantial differences between the mechanisms of HBV and HCV in induction of malignancy. Besides the oncogenic potential of viral proteins, HBV is a DNA virus able to integrate into the host DNA, directly triggering and transforming hepatocytes. In contrast, $\mathrm{HCV}$ (an RNA virus) is unable to integrate into the host genome, but it seems that viral proteins have more significant roles in hepatocarcinogenesis (10). Genomic studies on liver tissues have shown inconsistent gene expression profiles between HCC related to HBV and the one related to $\operatorname{HCV}(11,12)$. Proteomic analysis of the liver tissues has also revealed different protein profiles between HBV and HCV-infected patients (13). Although biomarker studies on liver tissues could be a useful strategy for determining new pathogenic biomarkers (for diagnostic and/or prognostic processes), serum has much priority for finding inexpensive, easily applicable, noninvasive biomarkers. Two-dimensional polyacrylamide gel electrophoresis (2-DE), in which comparisons can be made between normal and/or diseased samples, has a powerful capacity for separating thousands of proteins, including tissues and body fluids. This technique followed by protein identification with mass spectrometry has opened a new window for the discovery of biomarkers (2). By employing comparative proteomic approaches several putative serum HCC biomarkers have successfully been identified; such as heat shock protein27, C3, Apolipoprotein AI, haptoglobin (HP), $\alpha$-1-antitrypsin (AAT) and transthyretin (TTR) in HBV-infected patients and apolipoprotein C I and II, $\alpha$-anolase, transferrin, and galectin- 4 in HCV-infected cases $(2,8,11,13)$.

\section{Objectives}

We studied serum biomarkers during three stages in HBV-infected patients [chronic active hepatitis (CAH), cirrhosis, and HCC] and healthy individuals (14). In the present study, we have decided to:

a) Investigate serum proteomes among patients in the three stages of HCV infection and healthy individuals.

b) Compare the three stages of HCV infection with those in the same stage of HBV infection by using 2-DE coupled to liquid chromatography-tandem mass spectrometry. To the best of our knowledge, information on serum proteome profiles of HCC related to HBV and HCV is very limited. Identification of these differentially expressed proteins may provide possible specific serum biomarkers for the early diagnosis of HCC related to these hepatotropic viruses, and/or provide information for clarifying mechanisms of liver carcinogenesis related to these viruses.

\section{Patients and Methods}

\subsection{Subjects}

Patients $(\mathrm{N}=40)$ were recruited consecutively from the Departments of Gastroenterohepatology and Organ Transplant Surgery, Nemazie Hospital, Shiraz, Iran from September 2007 to July 2009. Characteristics of the study groups were obtained from patients' files, as shown in Tables 1 and 2.

\begin{tabular}{|c|c|c|c|c|c|c|c|}
\hline Characteristics & $\begin{array}{l}\text { Healthy } \\
(n=7)\end{array}$ & $\begin{array}{l}\text { CAH }^{\mathrm{a}}-\mathrm{HBV} \\
(\mathrm{n}=7)\end{array}$ & $\begin{array}{l}\text { C-HBV } \\
(n=7)\end{array}$ & HBV-HCC $(n=7)$ & CAH-HCV $(n=7)$ & C-HCV $(n=7)$ & HCV-HCC $(n=5)$ \\
\hline \multicolumn{8}{|l|}{ Sex } \\
\hline Male & 6 & 5 & 6 & 6 & 6 & 5 & 4 \\
\hline Female & 1 & 2 & 1 & 1 & 1 & 2 & 1 \\
\hline \multicolumn{8}{|l|}{ Age, $y$} \\
\hline$\left(\right.$ mean $\left.\pm S D^{\mathrm{a}}\right)$ & $42 \pm 7$ & $42 \pm 8$ & $40 \pm 7$ & $43 \pm 11$ & $42 \pm 11$ & $54 \pm 10$ & $39 \pm 12$ \\
\hline HBsAg ${ }^{\mathrm{a}}$ & - & + & + & + & - & - & - \\
\hline HBV DNA & & + & + & + & - & - & - \\
\hline HCVAb & - & - & - & - & + & + & + \\
\hline HCV RNA & - & - & - & - & + & + & + \\
\hline
\end{tabular}

${ }^{\mathrm{a}}$ Abbreviations: SD, standard deviation; HBsAg, hepatitis B surface antigen; CAH, chronic active hepatitis 


\begin{tabular}{|c|c|c|c|c|c|c|c|c|c|c|}
\hline No. & Age, y & Gender & $\begin{array}{l}\text { HBeAb/ } \\
\text { HBeAg }\end{array}$ & $\begin{array}{l}\text { HBcAb/ } \\
\text { HCVAb }\end{array}$ & $\begin{array}{l}\text { HBV/HCV } \\
\text { genotype }\end{array}$ & $\mathbf{A F P}^{\mathrm{a}}$ & $\mathbf{A L T}^{\mathrm{a}}$ & $\mathbf{A S T}^{\mathrm{a}}$ & Cirrhosis & Child-pugh \\
\hline 1 & 32 & M & $+1+$ & $+/-$ & $\mathrm{D}$ & 10.2 & 55 & 67 & + & B \\
\hline 2 & 53 & M & $+/-$ & $+\mid-$ & $\mathrm{D}$ & 11.4 & 134 & 163 & - & B \\
\hline 3 & 44 & $\mathrm{~F}$ & $+/-$ & $+\mid-$ & $\mathrm{D}$ & 14.1 & 107 & 146 & - & A \\
\hline 4 & 53 & M & $+/-$ & $+\mid-$ & $\mathrm{D}$ & 653 & 39 & 138 & + & C \\
\hline 5 & 51 & M & $+1+$ & $+1-$ & $\mathrm{D}$ & 724 & 107 & 166 & + & B \\
\hline 6 & 53 & M & $+/-$ & $+\mid-$ & $\mathrm{D}$ & 96.3 & 394 & 365 & + & B \\
\hline 7 & 54 & M & $+/-$ & $+/-$ & $\mathrm{D}$ & 1.3 & 37 & 22 & - & $\mathrm{C}$ \\
\hline 8 & 55 & M & $-F$ & $-1+$ & $\begin{array}{l}\text { Serum HCV } \\
\text { RNA was } \\
\text { negative }\end{array}$ & 15 & 43 & 127 & + & C \\
\hline 9 & 54 & M & $-1-$ & $-1+$ & $3 a$ & 6.2 & 52 & 80 & - & B \\
\hline 10 & 46 & M & $-H$ & $-1+$ & $3 a$ & 6 & 75 & 146 & + & B \\
\hline 11 & 47 & M & $-1-$ & $-1+$ & $1 \mathrm{a}$ & 5 & 105 & 144 & - & C \\
\hline 12 & 32 & M & -1 & $-1+$ & $\begin{array}{l}\text { Not deter- } \\
\text { mined }\end{array}$ & 8 & 26 & 28 & + & B \\
\hline
\end{tabular}

\footnotetext{
a Abbreviations: AFP, alpha-feto protein; ALT, Alanine aminoteransferase; AST, Aspartate aminoteransferase
}

There were 19 HCV-positive patients that included 7 with CAH, 7 with cirrhosis, and 5 with HCC. A total of 21 patients were HBV-positive of which 7 were diagnosed with CAH, 7 with cirrhosis, and 7 with HCC. Their diseases were confirmed by biochemical, virological, imaging, and pathological examinations. Included in this study were 7 age and sex matched healthy individuals with no histories of liver diseases, HBV and HCV laboratory signs, malignancies, and recent or chronic infectious diseases. Written informed consent was obtained from each participant before sampling. The Study was approved by the ethic committee of Shiraz University of Medical Sciences.

\subsection{Serum Samples}

A $5 \mathrm{~mL}$ blood sample was drawn from each participant and allowed to clot for $2 \mathrm{~h}$. Blood samples were spun at $3000 \mathrm{rpm}$ for $10 \mathrm{~min}$ and the serum was separated, aliquoted, and stored at $-70^{\circ} \mathrm{C}$ until tested. In order to increase serum protein resolution, high abundant proteins that included albumin and immunoglobulin (Ig) G were depleted from $60 \mu \mathrm{L}$ of serum by the Arum Protein Mini Kit (Bio Rad, Hercules, CA, USA). Subsequently, protein concentration of the depleted sera was determined by a Bradford protein assay, using albumin as the standard.

\subsection{Laboratory Tests}

HBV and HCV genotyping was performed using polymerase chain reaction-restriction fragment length polymorphisms and genotype specific primers respectively, as previously described $(15,16)$. $\alpha$-fetoprotein was detected by commercial quantities Enzyme linked Immunosorbent Assay kits (ConAg, Sweden) according to the manu- factures' instructions.

\subsection{2-DE}

Briefly, approximately $100 \mu \mathrm{g}$ of proteins were loaded into immobilized pH gradient strips pH 3-10 linear (BioRad, Hercules, CA, USA) in first dimensional isoelectric focusing. The rehydration solution contained $8 \mathrm{M}$ urea, 3\% CHAPS, 2\% immobilized pH gradient buffer ( $\mathrm{pH} 3-10$ ), 50 $\mathrm{mM}$ Dithiothreitol and a trace amount of bromophenol blue. The strips were focused at $80000 \mathrm{Vh}$. The focused strips were equilibrated and reduced to $10 \mathrm{~mL}$ equilibration buffer [50 mM Tris (pH 8.8), 6 M urea, 30\% (w/v) glycerol, $2 \%(\mathrm{w} / \mathrm{v}$ ) sodium dodecyl sulfate] that contained $1 \%$ $(\mathrm{w} / \mathrm{v})$ Dithiothreitol for $15 \mathrm{~min}$ and alkylated in another $10 \mathrm{~mL}$ equilibration buffer that contained $2.5 \%(\mathrm{w} / \mathrm{v})$ idoacetamide for $15 \mathrm{~min}$. The strips were sealed on top of a $12.5 \%$ sodium dodecyl sulfate gel using $0.5 \%$ agarose. The second dimensional electrophoresis was performed in the protean II xi cell (Bio-Rad). Electrophoresis was run at $10 \mathrm{~mA}$ per gel for $30 \mathrm{~min}$ followed by $25 \mathrm{~mA}$ per gel until the tracking dye reached the bottom of the gels. The gels were visualized by using a complete protocol of a silver staining method for analytical gels. For preparative gels, the method was modified to make the standard protocol compatible with mass spectrometry analysis (17).

The silver-stained gels were scanned using a GS-800 calibrated densitometer (Bio-Rad) at $300 \mathrm{dpi}$. Gel images were analyzed by Prognosis software (Nonlinear, Newcastle-upon-Tyne, UK) according to the instruction procedure for differentially expressed proteins. The protein spots whose normalized volumes changed more than 1.5 fold and with $\mathrm{P}<0.05$ were picked up from the gels that 
had been stained with the mass spectrometry compatible method.

\subsection{In-gel Digestion and Liquid Chromatography- Tandem Mass Spectrometry Analysis}

In-gel digestion was carried out as previosly described (18). For liquid chromatography-tandem mass spectrometry analysis, the lyophilized samples were resuspended in $0.1 \%$ formic acid before analysis. An Agilent 1100 LC/ MSD trap XCT was used for high-performance liquid chromatography and tandem mass spectrometry. The mobile phase A of liquid chromatography was water/0.1\% formic acid and the mobile phase $B$ was acetonitril/0.1\% formic acid. A trap column (Agilent, G 1375-87320,105 mm, $25 \mu \mathrm{m}$, Germany) was connected to a standard column (Zobrax 300 SB-C18, $75 \mathrm{~mm}, 3.5 \mu \mathrm{m}$ ). Twelve $\mu \mathrm{L}$ of the peptide was loaded on a trapping column and desalted by washing with $2 \%$ B for 5 min. A linear gradient from $2 \%-60 \%$ of concentration B in $55 \mathrm{~min}$, then $80 \% \mathrm{~B}$ in $8 \mathrm{~min}$, and re-equilibration of $2 \% \mathrm{~B}$ in $10 \mathrm{~min}$, was applied to elute peptides at a flow rate of $300 \mathrm{~nL} / \mathrm{min}$. The mass spectrometer was operated in positive ion mode over the range of 350-1850 $\mathrm{m} / \mathrm{z}$. Tandem mass spectrometry data were analyzed with spectrum mill (Agilent, Palo Alto, CA, USA) against the Swiss-Prot database (released May, 2010). The following filters were used after database searching: peptide score 8 , peptide \% SPI $>70$ and protein score 10 .

\section{Results}

In the present study, serum proteome analysis was carried out for 7 healthy individuals and 19 HCV-positive patients in three stages ( 7 with CAH, 7 with cirrhosis, and 5 with HCC). Serum proteomes of the 19 HCV-positive patients were further compared to those from $21 \mathrm{HBV}$ positive patients ( 7 with $\mathrm{CAH}, 7$ with cirrhosis, and 7 with HCC) who were of the same stage. Among these groups, 62 protein spots were differentially expressed ( $\geq 1.5$ fold; $\mathrm{P}<0.05$; Table 3). Of these, 42 spots were identified by MS. The identified spots corresponded with 15 proteins. Table 3 displays the molecular weights (MW), pI, accession numbers, and proposal function of the identified proteins. The locations of these spots on the gels are shown in Figure 1.

There was no differentially expressed protein spots between $\mathrm{CAH}$ related to $\mathrm{HBV}$ and $\mathrm{CAH}$ related to $\mathrm{HCV}$ infections. However, comparisons of other stages revealed several differential protein spots as below.

\subsection{Healthy Individuals Versus HCV-Positive Pa- tients}

Differentially expressed proteins among these four groups were HP $\alpha$ and $\alpha 2$ isoforms, clusterin (CLU), reti

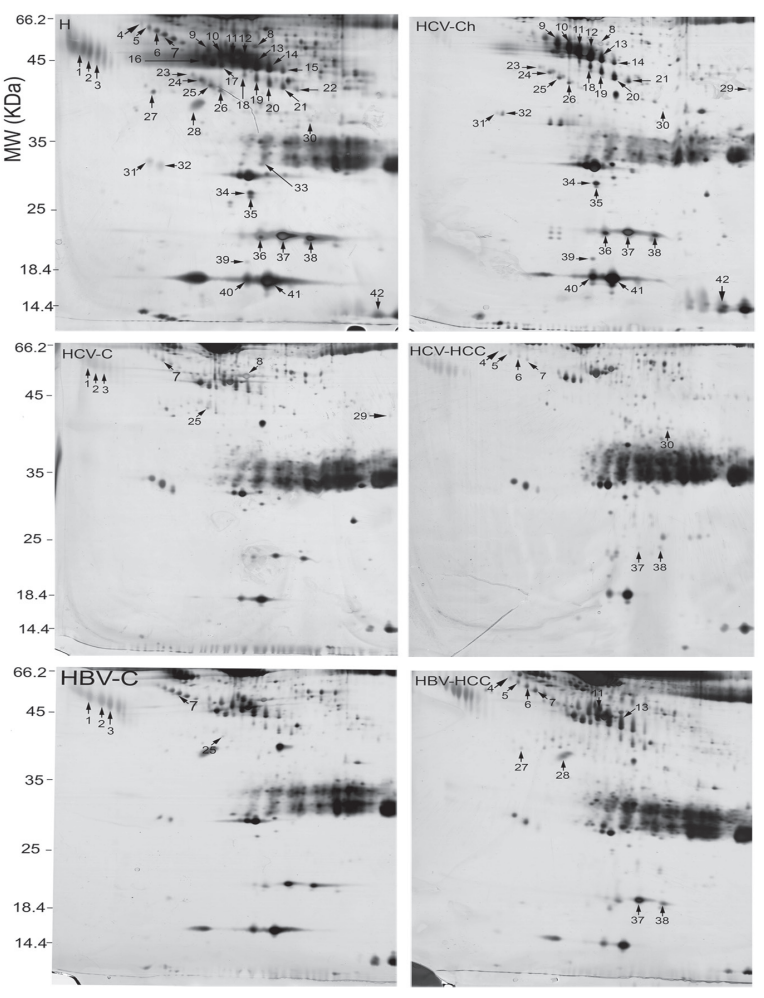

Figure 1. Identified Differentially Expressed Spots Among 2-DE Gels of the Sera From Healthy Individuals (H), Chronic Active Hepatitis (Ch), Cirrhosis (C), and HCC Associated With HCV and HBVInfections Were Numbered. Spot numbers are for cross-reference with Table 3 and Figures 2-4.

nol binding protein, TTR, albumin, a1-acid glycoprotein (AGP), hemoglobin delta, Ig J chain, Ig gamma chain c, C3, zinc- $\alpha$ glycoprotein, and CD5-like antigen (CD5L) (Table 3).

\subsection{CAH-HCV Patients Versus Cirrhosis-HCV Pa- tients}

Analysis of serum protein expressions between $\mathrm{CAH}$ and cirrhosis in HCV-positive patients revealed 35 differentially expressed protein spots. From these, 25 were identified by MS. HP $\alpha$ and $\alpha-2$ isoforms, CLU, retinol binding protein, TTR, albumin, AGP and hemoglobin delta were decreased in the cirrhosis stage but IgJ chain was increased.

\subsection{Cirrhosis-HCV Patients Versus HCC-HCV Pa- tients}

We observed differential expression of 13 protein spots between cirrhosis and HCC patients with HCV infection. From these, 2 protein spots were identified by MS. CD5L $(>1.6$ fold; $\mathrm{P}=0.022$ ) was up regulated in HCC patients but Ig gamma chain $\mathrm{C}(>3.4$ fold; $\mathrm{P}<0.042)$ was down regulated in this group (Figure 2 ). 
Table 3. List of 42 Protein Spots Identified By Liquid Chromatography-Tandem Mass Spectrometry. Spot Numbers are Related to Figures 1-4

\begin{tabular}{|c|c|c|c|c|c|c|}
\hline Spot No. & Protein name & $\operatorname{Mr}^{\mathrm{a}}\left(\operatorname{Pre}^{\mathrm{a}} / \operatorname{Exp}^{\mathrm{a}}\right)$ & $\mathrm{PI}^{\mathrm{a}}($ Pre/Exp) & Acc $^{\text {a No. }}$ & Coverage, $\%$ & Function \\
\hline $\mathbf{1}$ & $\alpha-1$ acid glycoprotein & $23.5 / 44$ & $4.93 / 4$ & P02763 & 8 & Immune system \\
\hline 2 & $\alpha-1$ acid glycoprotein & $23.5 / 43$ & $4.93 / 4.7$ & P02763 & 8 & Immune system \\
\hline 3 & $\alpha-1$ acid glycoprotein & $23.5 / 43$ & $4.93 / 4.7$ & P02763 & 8 & Immune system \\
\hline 4 & Leucine-rich $\alpha$-2-glycoprotein & $38.1 / 48$ & $6.45 / 4.3$ & P02750 & 3 & Unknown \\
\hline 5 & Leucine-rich $\alpha$-2-glycoprotein & $38.1 / 47$ & $6.45 / 4.4$ & P02750 & 38 & Unknown \\
\hline 6 & Leucine-rich $\alpha$-2-glycoprotein & $38.1 / 46$ & $6.45 / 4.6$ & P02750 & 24 & Unknown \\
\hline 7 & Leucine-rich $\alpha$-2-glycoprotein & $38.1 / 45$ & $6.45 / 4.7$ & P02750 & 10 & Unknown \\
\hline 8 & CD5-like antigen & $38 / 40.5$ & $5.28 / 5.85$ & O43866 & 22 & Immune system \\
\hline 9 & Haptoglobin- $\alpha$ chain & $45.2 / 42$ & $6.13 / 5.3$ & P00738 & 7 & Hemoglobin scavenger \\
\hline 10 & Haptoglobin- $\alpha$ chain & $45.2 / 41$ & $6.13 / 5.4$ & P00738 & 24 & Hemoglobin scavenger \\
\hline 11 & Haptoglobin- $\alpha$ chain & $45.2 / 39$ & $6.13 / 5.6$ & P00738 & 14 & Hemoglobin scavenger \\
\hline 12 & Haptoglobin- $\alpha$ chain & $45.2 / 38$ & $6.13 / 5.75$ & P00738 & 30 & Hemoglobin scavenger \\
\hline 13 & Haptoglobin- $\alpha$ chain & $45.2 / 37.5$ & $6.13 / 5.85$ & P00738 & 4 & Hemoglobin scavenger \\
\hline 14 & Haptoglobin- $\alpha$ chain & $45.2 / 37$ & $6.13 / 6$ & P00738 & 10 & Hemoglobin scavenger \\
\hline 15 & Haptoglobin- $\alpha$ chain & $45.2 / 35.5$ & $6.13 / 6.2$ & P00738 & 30 & Hemoglobin scavenger \\
\hline 18 & Haptoglobin cleaved- $\alpha$ chain & $45.2 / 36$ & $6.13 / 5.7$ & P00738 & 23 & Hemoglobin scavenger \\
\hline 19 & Haptoglobin cleaved- $\alpha$ chain & $45.2 / 35$ & $6.13 / 5.85$ & P00738 & 8 & Hemoglobin scavenger \\
\hline 20 & Haptoglobin cleaved- $\alpha$ chain & $45.2 / 34$ & $6.13 / 6.1$ & P00738 & 38 & Hemoglobin scavenger \\
\hline 21 & Haptoglobin cleaved- $\alpha$ chain & $45.2 / 33.5$ & $6.13 / 6.2$ & P00738 & 33 & Hemoglobin scavenger \\
\hline 22 & Haptoglobin cleaved- $\alpha$ chain & $45.2 / 33$ & $6.13 / 6.25$ & P00738 & 6 & Hemoglobin scavenger \\
\hline 36 & Haptoglobin- $\alpha 2$ chain & $45.2 / 17$ & $6.13 / 5.9$ & P00738 & 21 & Hemoglobin scavenger \\
\hline 37 & Haptoglobin- $\alpha 2$ chain & $45.2 / 17$ & $6.13 / 6.2$ & P00738 & 16 & Hemoglobin scavenger \\
\hline 38 & Haptoglobin- $\alpha 2$ chain & $45.2 / 17$ & $6.13 / 6.6$ & P00738 & 25 & Hemoglobin scavenger \\
\hline 16 & Complement C3 & $187.1 / 39$ & $6.02 / 5.05$ & P01024 & 16 & Innate immunity \\
\hline 17 & Zinc- $\alpha$-2-glycoprotein & $33.8 / 38$ & $5.57 / 5.3$ & P25311 & 4 & Stimulate lipolysis \\
\hline 23 & Clusterin & $52.4 / 36$ & $5.89 / 5.1$ & P10909 & 5 & Unknown \\
\hline 24 & Clusterin & $52.4 / 35$ & $5.89 / 5.2$ & P10909 & 32 & Unknown \\
\hline 25 & Clusterin & $52.4 / 34$ & $5.89 / 5.3$ & P10909 & 5 & Unknown \\
\hline 26 & Clusterin & $52.4 / 33$ & $5.89 / 5.4$ & P10909 & 24 & Unknown \\
\hline 27 & $\alpha-1$-antitrypsin & $46.7 / 33$ & $5.37 / 4.7$ & P01009 & 13 & Protease inhibitor \\
\hline 28 & Transthyretin & $15.8 / 33$ & $5.52 / 5.2$ & P02766 & 54 & $\begin{array}{l}\text { Thyroxine hormone } \\
\text { carrier }\end{array}$ \\
\hline 40 & Transthyretin & $15.8 / 14.4$ & $5.52 / 5.8$ & P02766 & 15 & $\begin{array}{l}\text { Thyroxine hormone } \\
\text { carrier }\end{array}$ \\
\hline 41 & Transthyretin & $15.8 / 14.4$ & $5.52 / 6.1$ & P02766 & 41 & $\begin{array}{l}\text { Thyroxine hormone } \\
\text { carrier }\end{array}$ \\
\hline 29 & $\begin{array}{l}\text { Immunoglobulin gamma- } \\
\text { 2-chain C }\end{array}$ & $35.9 / 35$ & $7.66 / 7.5$ & P01859 & 24 & Adaptive immunity \\
\hline 30 & Ficolin 3 & $32.9 / 31$ & $6.2 / 6.75$ & O75636 & 8 & Innate immunity \\
\hline 31 & Immunoglobulin J chain & $15.5 / 23$ & $4.62 / 4.4$ & P01591 & 44 & $\begin{array}{l}\text { IgA and IgM linker } \\
\text { protein }\end{array}$ \\
\hline 32 & Immunoglobulin J chain & $15.5 / 23$ & $4.62 / 4.6$ & P01591 & 31 & $\begin{array}{l}\text { IgA and IgM linker } \\
\text { protein }\end{array}$ \\
\hline 33 & $\begin{array}{l}\text { Immunoglobulin kappa } \\
\text { chain }\end{array}$ & $11.6 / 24$ & $5.58 / 5.65$ & P01838 & 33 & Adaptive immunity \\
\hline
\end{tabular}




\begin{tabular}{|c|c|c|c|c|c|c|}
\hline 34 & Retinol-binding protein & $23 / 21.5$ & $5.76 / 5.8$ & P02753 & 6 & Carrier \\
\hline 35 & Retinol-binding protein & $23 / 21$ & $5.75 / 5.8$ & P02753 & 29 & Carrier \\
\hline 39 & Albumin & $69.3 / 16$ & $5.92 / 5.8$ & P02768 & 8 & Carrier \\
\hline 42 & Hemoglobin subunit delta & $16 / 13$ & $7.84 / 7.8$ & P02042 & 9 & Oxygen transport \\
\hline
\end{tabular}

a Abbreviations: Pre, Predicated; Exp, experimental; PI, Isoelectric point; Acc, Accession numbers; Mr, Relative molecular mass

\subsection{Cirrhosis-HBV Patients Versus Cirrhosis-HCV Patients}

Of the seven differentially expressed protein spots between the two groups, six were identified by MS. In HBV patients with cirrhosis, AGP was up regulated in three spots; also, CLU and leucine-rich $\alpha$-2-glycoprotein (LRG) were up regulated and Ig gamma chain $C$ was down regulated in this group compared to HCV cirrhosis (Figure 3).

\subsection{HCC-HBV Patients Versus HCC-HCV Patients}

This analysis showed 21 protein spots differentially expressed between these groups. Of them, 11 were identified by MS as belonging to 5 different proteins. LRG ( 4 spots), HP $\alpha-2$ isoforms (2 spots), HP- $\alpha$ isoforms (2 spots), TTR, and AAT were up regulated in HBV-HCC patients compared to HCV-HCC patients; but ficolin-3 was down regulated in this group (Figure 4).

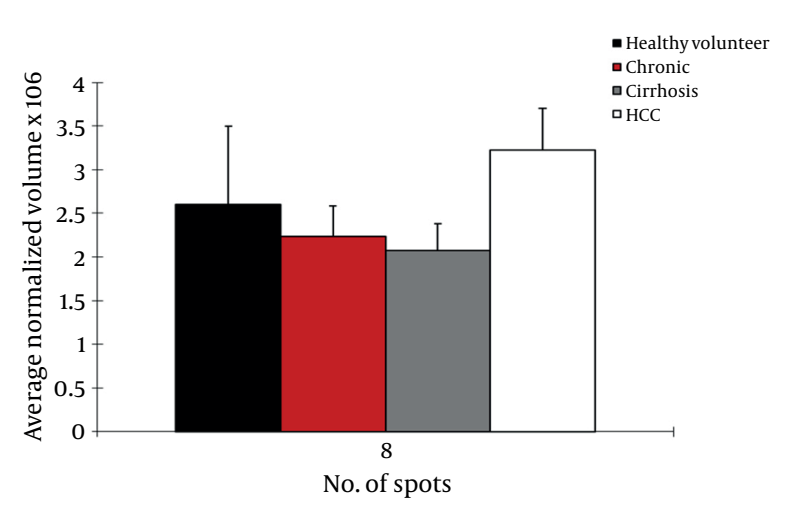

Figure 2. Normalized Volume Intensity of CD5-Like Antigen (Spot no. 8) in the Sera From Healthy Volunteers, CAH, Cirrhosis, and HCC Patients Related to HCV

\section{Discussion}

Advance in proteomic and genomic studies in recent years have highlighted heterogeneity in pathogenesis of HCC. A number of proteins and genes have been identified with differentially expression in HCV- and HBV-infected patients with liver pathology (10). We investigated the serum proteomes in individuals with three stages of HCV infection (CAH, cirrhosis, and HCC) and healthy individuals by 2 -DE coupled to mass spectrometry and compared them to those of similar stages in HBV infection. In the HCV-infected patients, we found increased CD5L exp-

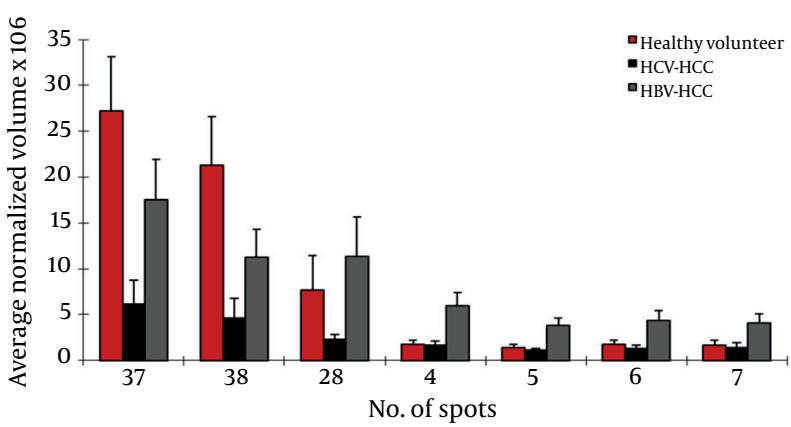

Figure 3. Normalized Volume Intensity of Haptoglobin- $\alpha$ Isoforms (Spots No. 37, 38), Transthyretin (Spot No. 28) and Leucine Rich $\alpha 2$ Glycoprotein (Spots No. 4-7) Between HCC Associated With HBV and HCV Patients.

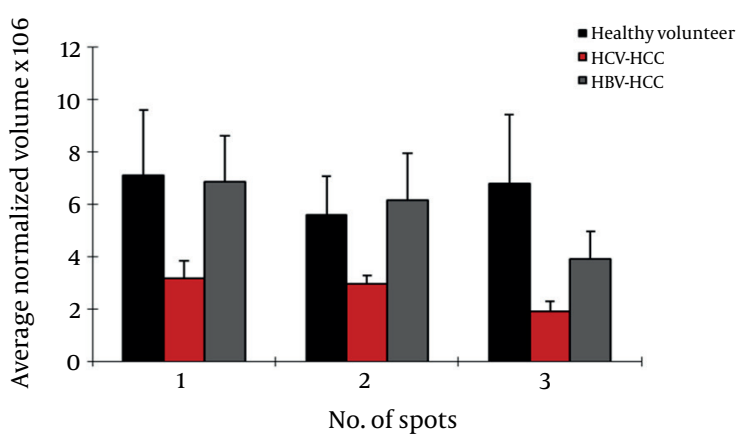

Figure 4. Normalized Volume Intensity of a1-Acid Glycoprotein (Spots no. 1-3) Between Patients With Cirrhosis Related to HBV and HCV.

-ression at the HCC stage compared to cirrhosis. An increased serum level of CD5L has been reported in HCVcirrhotic compared to mild fibrosis patients by Gangadharan et al. (19), in cirrhotic and HCC patients compared to pre-cirrhotic disease related to non-alcoholic fatty liver disease by Gray et al. (20), and in Kawasaki disease and atopic dermatitis (20-22). Increased expression of CD5L mRNA has also been reported in cirrhotic and cancerous liver tissues (20). Our report is the first one to show over-expression of CD5L in HCV-HCC compared to $\mathrm{HCV}$-cirrhosis. CD5L is a secreted glycoprotein belonging to the scavenger receptor cysteine-rich super-family. It is expressed by macrophages present in both primary and secondary lymphoid tissues including the thymus, bone marrow, spleen, and lymph nodes. CD5L binds to 
myelomonocytic and lymphoid cells, suggesting that it may play a role in the regulation of both the innate and adaptive immune systems (23). Evidence suggests an association of CD5L with $\operatorname{IgM}(24)$, an antibody that is a costeffective serological marker of active viral replication in HCV-infected patients (23-25). The exact function of CD5L is not clear. Recently, Haruta et al. have shown that CD5L supports macrophage survival and activity in Corynebacterium parvum-induced hepatitis in mice (21). Due to the association of CD5L with the immune system, an increase in expression of CD5L in HCV-HCC patients compared to those with cirrhosis may reflect the nature of an immune response to HCV infection. Simultaneously, it may be considered a variation in the oncogenic behavior of HCV in HCC patients compared to cirrhotic patients with HCV. We have previously investigated differentially expressed serum proteins among CAH, cirrhosis, and HCC stages of HBV infection and healthy individuals by 2-DE coupled to mass spectrometry (14). Here we compared the serum proteomes of these stages of HCV infection versus HBV infection. These comparisons revealed different expressions of several key proteins, notably LRG, HP $\alpha$-2 isoforms, TTR, and AGP. LRG was one of the serum-overexpressed proteins in HBV-HCC compared to HCV-HCC patients. LRG down regulation has been reported in HCV-cirrhotic patients when compared to mild fibrosis (26). It has been reported that the serum level of this protein has increased in malignancies such as lung and ovarian cancer, as well as bacterial and viral infections (27). LRG was first isolated from serum (28). Although liver cells appear to be the major source of this protein, it is also produced by mature neutrophils and endothelial venules of the mesenteric tissues (27). Its real physiological functions have not yet been clarified. LGR is induced by interleukin-6, interleukin-1-beta and transforming growth factor-alpha in hepatoma cells, and is over-expressed in livers of the mice challenged by lipopolysaccharide, rendering it an acute phase protein. With the current knowledge, the reason for LRG level differences between HBV-HCC and HCV-HCC is not clear. LRG is suggested to be a marker for poor prognosis in HCC (29). HP is a tetramer molecule composed of two á subunits (9.1 kDa) and two $\beta$ subunits (40 kDa). Although the liver is the major source of serum HP, it is also secreted by some cancer cells (30). HP is a positive acute phase protein and has long been used for the study of various liver diseases such as viral hepatitis and HCC (31). We have identified 15 spots as HP, 3 of which were HP$\alpha 2$ and the remainders were of the HP- $\alpha$ chain. Only two spots of the HP- $\alpha 2$ chain were differentially expressed between HBV-HCC and HCV-HCC patients. We have previously observed the differential expression of some HP isoforms between HBV-HCC and HBV-cirrhosis (14). In keeping with our data, specific HP profiles have been reported in breast, ovarian, head and neck cancers (32). Different HP isoforms may show different biological functions, and their occurrences might be associated with diseasespecific alterations in the intercellular processes such as post-translational modification mechanisms. In this regard, Ang et al. have reported that HPs with different degrees of glycosylation are produced by HCC tissue, while other HP glycoforms are produced by normal cells (30). We have found 3 spots as TTR, one of which was of multimeric form. The multimeric form of the serum TTR increased (4.9 fold) in HBV-HCC patients compared to HCVHCC patients. Also, two of the monomeric forms were down regulated (5.6 fold) in the cirrhosis patients sera compared to CAH associated with HBV. TTR (also called prealbumin) is presented in the serum and cerebrospinal fluid that has been synthesized and secreted by liver cells and the choroid plexus of the brain. The two significant physiological functions of TTR are transport of thyroxin (T4) and retinol (vitamin A) (33). Considering the fact that the liver is the source of serum TTR, it is reasonable to assume that the synthesis of this protein varies in liver diseases such as cancer and hepatitis. The mRNA level of this protein was decreased after treatment of HepG2 cells with interleukin-6, interleukin-1, or transforming growth factor alpha (34). TTR can inhibit interleukin-1 production by monocytes and endothelial cells, thus showing anti-inflammatory properties (35). Our finding in the 2-DE analysis has suggested conformational changes of TTR in HCC patients related to HBV and HCV. Differential expressions of TTR in the sera have been reported in SARS, dengue fever, ovarian cancer, malignant melanoma, and in the cerebrospinal fluid of some neurological disorders such as Alzheimer's, Parkinson, and schizophrenia (34, $36,37)$. We found down regulation of AGP in HCV-cirrhotic patients compared to those with HBV. AGP is an acute phase serum glycoprotein synthesized and secreted by the liver. AGP is an indicator of liver failure after liver resection (38). A change in concentration and glycosylation of AGP is known to be related to the pathogenesis of liver diseases. It increases in patients with acute hepatitis and HCC, but decreases in patients with chronic hepatitis and liver cirrhosis (39). Since AGP is synthesized and secreted by hepatocytes, damage and injury to liver parenchyma can affect the serum concentration of this protein. Decreased expression of AGP in HCV-cirrhotic patients results in massive liver tissue damage in HCV compared to HBV cirrhotic patients that may be associated with different hepatopathogenesis mechanisms induced by these hepatotropic viruses. Although we have identified several differentially expressed proteins among different stages of HCV infection and compared them to those in different stages of HBV infection, some limitations still exist. The identified proteins should be confirmed by other techniques such as western blotting, real-time PCR or ELISA in a larger number of the patients. In conclusion, differentially expressed proteins, e.g. CD5L, in the sera from $\mathrm{CAH}$, cirrhosis, and HCC related to HCV were identified using a proteomic approach. We have also compared, for the first time, the serum proteomes of these three main stages of HCV infection with the same stages of HBV infection and identified some relevant differentially ex- 
pressed proteins such as LRG and HP $\alpha 2$ isoforms. Further studies are required to confirm the differential expression of the identified proteins and their significance as disease biomarkers.

\section{Acknowledgements}

This work was supported by grants from Shiraz Institute for Cancer Research (No. ICR-87-503), and Kiban Kenkyu Hi from Yamaguchi University Graduate School of Medicine.

\section{Authors' Contributions}

Study concept: GA, S M; Study design: M Z, S J; Bench work: S J; patients and control selection: T SA; data analysis: S J, Y K, N K; Manuscript drafting: S J and M Z; Critical revision of manuscript: $\mathrm{GA}, \mathrm{KN}, \mathrm{S} \mathrm{M}$ and $\mathrm{YK}$.

\section{Financial Disclosure}

Authors declare they have no financial disclosure.

\section{Funding Support}

This work was supported by grants from Shiraz Institute for Cancer Research (No. ICR-87-503), and Kiban Kenkyu Hi from Yamaguchi University Graduate School of Medicine.

\section{References}

1. Yang JD, Roberts LR. Hepatocellular carcinoma: A global view. Nat Rev Gastroenterol Hepatol. 2010;7(8):448-58.

2. Kuramitsu Y, Nakamura K. Proteomic analysis of cancer tissues: shedding light on carcinogenesis and possible biomarkers. Proteomics. 2006;6(20):5650-61.

3. Lavanchy D. The global burden of hepatitis C. Liver Int. 2009;29 Suppl 1:74-81.

4. McMahon BJ. The natural history of chronic hepatitis B virus infection. Hepatology. 2009;49(5 Suppl):S45-55.

5. El-Serag HB, Rudolph KL. Hepatocellular carcinoma: epidemiology and molecular carcinogenesis. Gastroenterology. 2007;132(7):2557-76.

6. Fattovich G. Natural history and prognosis of hepatitis B. Semin Liver Dis. 2003;23(1):47-58.

7. Fattovich G, Stroffolini T, Zagni I, Donato F. Hepatocellular carcinoma in cirrhosis: incidence and risk factors. Gastroenterology. 2004;127(5 Suppl 1):S35-50

8. Takashima M, Kuramitsu Y, Yokoyama Y, Iizuka N, Harada T, Fujimoto M, et al. Proteomic analysis of autoantibodies in patients with hepatocellular carcinoma. Proteomics. 2006;6(13):3894-900.

9. Pateron D, Ganne N, Trinchet JC, Aurousseau MH, Mal F, Meicler C, et al. Prospective study of screening for hepatocellular carcinoma in Caucasian patients with cirrhosis. J Hepatol. 1994;20(1):65-71.

10. Tsai WL, Chung RT. Viral hepatocarcinogenesis. Oncogene. 2010;29(16):2309-24

11. Kuramitsu Y, Nakamura K. Current progress in proteomic study of hepatitis $\mathrm{C}$ virus-related human hepatocellular carcinoma. Expert Rev Proteomics. 2005;2(4):589-601.

12. Miyagawa S, Kawasaki S, Makuuchi M. Comparison of the characteristics of hepatocellular carcinoma between hepatitis B and $C$ viral infection: tumor multicentricity in cirrhotic liver with hepatitis C. Hepatology. 1996;24(2):307-10.

13. Kim W, Oe Lim S, Kim JS, Ryu YH, Byeon JY, Kim HJ, et al. Comparison of proteome between hepatitis $\mathrm{B}$ virus- and hepatitis
C virus-associated hepatocellular carcinoma. Clin Cancer Res. 2003;9(15):5493-500.

14. Sarvari J, Mojtahedi Z, Kuramitsu Y, Malek-Hosseini SA, Shams Shahrabadi M, Ghaderi A, et al. Differential expression of haptoglobin isoforms in chronic active hepatitis, cirrhosis and HCC related to HBV infection. Oncol Lett. 2011;2(5):871-877.

15. Keyvani H, Alizadeh AH, Alavian SM, Ranjbar M, Hatami S. Distribution frequency of hepatitis $\mathrm{C}$ virus genotypes in 2231 patients in Iran. Hepatol Res. 2007;37(2):101-3.

16. Mojiri A, Behzad-Behbahani A, Saberifirozi M, Ardabili M, Beheshti M, Rahsaz M, et al. Hepatitis B virus genotypes in southwest Iran: molecular, serological and clinical outcomes. World Gastroenterol. 2008;14(10):1510-3.

17. Yan JX, Wait R, Berkelman T, Harry RA, Westbrook JA, Wheeler $\mathrm{CH}$, et al. A modified silver staining protocol for visualization of proteins compatible with matrix-assisted laser desorption/ ionization and electrospray ionization-mass spectrometry. Elec trophoresis. 2000;21(17):3666-72.

18. Yousefi Z, Sarvari J, Nakamura K, Kuramitsu Y, Ghaderi A, Mojtahedi Z. Secretomic analysis of large cell lung cancer cell lines using two-dimensional gel electrophoresis coupled to mass spectrometry. Folia Histochem Cytobiol. 2012;50(3):368-74

19. Gangadharan B, Antrobus R, Dwek RA, Zitzmann N. Novel serum biomarker candidates for liver fibrosis in hepatitis $C$ patients. Clin Chem. 2007;53(10):1792-9.

20. Gray J, Chattopadhyay D, Beale GS, Patman GL, Miele L, King BP et al. A proteomic strategy to identify novel serum biomarkers for liver cirrhosis and hepatocellular cancer in individuals with fatty liver disease. BMC Cancer. 2009;9:271

21. Kim WK, Hwang HR, Kim do H, Lee PY, In YJ, Ryu HY, et al. Glycoproteomic analysis of plasma from patients with atopic dermatitis: CD5L and ApoE as potential biomarkers. Exp Mol Med. 2008;40(6):677-85.

22. Yu HR, Kuo HC, Sheen JM, Wang L, Lin IC, Wang CL, et al. A unique plasma proteomic profiling with imbalanced fibrinogen cascade in patients with Kawasaki disease. Pediatr Allergy Immunol. 2009;20(7):699-707.

23. Sarrias MR, Rosello S, Sanchez-Barbero F, Sierra JM, Vila J, Yelamos J, et al. A role for human Sp alpha as a pattern recognition receptor. J Biol Chem. 2005;280(42):35391-8.

24. Sarrias MR, Padilla O, Monreal Y, Carrascal M, Abian J, Vives J, et al. Biochemical characterization of recombinant and circulating human Spalpha. Tissue Antigens. 2004;63(4):335-44.

25. Tabone M, Secreto P, Marini C, Bonardi R, Boero M, Taraglio S, et al Pre-treatment levels of anti-HCV core IgM antibodies are closely associated with response to alpha interferon therapy in chronic hepatitis C patients. Eur J Gastroenterol Hepatol. 1997;9(3):287-91.

26. Cheung KJ, Tilleman K, Deforce D, Colle I, Van Vlierberghe H. The HCV serum proteome: a search for fibrosis protein markers. J Viral Hepat. 2009;16(6):418-29.

27. Andersen JD, Boylan KL, Xue FS, Anderson LB, Witthuhn BA Markowski TW, et al. Identification of candidate biomarkers in ovarian cancer serum by depletion of highly abundant proteins and differential in-gel electrophoresis. Electrophoresis. 2010;31(4):599-610.

28. Haupt H, Baudner S. [Isolation and characterization of an unknown, leucine-rich 3.1-S-alpha2-glycoprotein from human serum (author's transl)]. Hoppe Seylers Z Physiol Chem. 1977;358(6):639-46

29. Tanizaki H, Ryu M, Kinoshita T, Kawano N, Konishi M, Cho A, et al. Comparison of clinical features and survival in patients with hepatitis B and C virus-related hepatocellular carcinoma. Jpn J Clin Oncol. 1997;27(2):67-70.

30. Lee J, Wu CC, Lee KJ, Chuang TH, Katakura K, Liu YT, et al. Activation of anti-hepatitis $C$ virus responses via Toll-like receptor 7 . Proc Natl Acad Sci U S A. 2006;103(6):1828-33.

31. Ahmed N, Barker G, Oliva KT, Hoffmann P, Riley C, Reeve S, et al. Proteomic-based identification of haptoglobin-1 precursor as a novel circulating biomarker of ovarian cancer. Br J Cancer 2004;91(1):129-40.

32. Chen CB, Su YC, Huang TT, Ho HC, Chang YT, Tung YT, et al. Differentially expressed serum haptoglobin alpha chain isoforms 
with potential application for diagnosis of head and neck cancer. Clin Chim Acta. 2008;398(1-2):48-52.

33. Fleming CE, Nunes AF, Sousa MM. Transthyretin: more than meets the eye. Prog Neurobiol. 2009;89(3):266-76.

34. Albuquerque LM, Trugilho MR, Chapeaurouge A, Jurgilas PB Bozza PT, Bozza FA, et al. Two-dimensional difference gel electrophoresis (DiGE) analysis of plasmas from dengue fever patients. J Proteome Res. 2009;8(12):5431-41.

35. Borish L, King MS, Mascali JJ, Johnson S, Coll B, Rosenwasser LJ. Transthyretin is an inhibitor of monocyte and endothelial cell interleukin-1 production. Inflammation.1992;16(5):471-84.

36. Quaye IK. Haptoglobin, inflammation and disease. Trans $R$ Soc Trop Med Hyg. 2008;102(8):735-42.

37. Zhang Z, Bast RC, Jr, Yu Y, Li J, Sokoll LJ, Rai AJ, et al. Three biomarkers identified from serum proteomic analysis for the detection of early stage ovarian cancer. Cancer Res. 2004;64(16):5882-90.

38. Ren F, Chen Y, Wang Y, Yan Y, Zhao J, Ding M, et al. Comparative serum proteomic analysis of patients with acute-on-chronic liver failure: alpha-1-acid glycoprotein maybe a candidate marker for prognosis of hepatitis B virus infection. J Viral Hepat. 2010;17(11):816-24.

39. Mondal G, Chatterjee U, Das HR, Chatterjee BP. Enhanced expression of alpha1-acid glycoprotein and fucosylation in hepatitis B patients provides an insight into pathogenesis. Glycoconj $J$. 2009;26(9):1225-34.

Please cite this paper as: Sarvari J, Mojtahedi Z, Taghavi AR, Kuramitsu Y, Shamsi Shahrabadi M, Ghaderi B, Nakamura K. Differentially Expressed Proteins in Chronic Active Hepatitis, Cirrhosis, and HCC Related to HCV Infection in Comparison With HBV Infection: A proteomics study. Hepat Mon. 2013;13(7):e10106. DOI:10.5812/ hepatmon.8351 